\title{
The most appropriate titanium mesh cage size for anterior spinal reconstruction after single-level lumbar total en bloc spondylectomy: a finite element analysis and cadaveric validation study
}

Permsak Paholpak ${ }^{1,2^{*}}$ (D), Winai Sirichativapee ${ }^{1,2}$, Taweechok Wisanuyotin ${ }^{1,2}$, Weerachai Kosuwon ${ }^{1,2}$, Yuichi Kasai ${ }^{1,2}$ and Hideki Murakami ${ }^{3}$

\begin{abstract}
Purpose: There is little information available regarding the cage diameter that can provide the most rigid construct reconstruction after total en bloc spondylectomy (TES). The aim of this study was thus to determine the most appropriate titanium mesh cage diameter for reconstruction after spondylectomy.

Methods: A finite element model of the single level lumbar TES was created. Six models of titanium mesh cage with diameters of $1 / 3,1 / 2,2 / 3,3 / 4,4 / 5$ of the caudad adjacent vertebra, and $1 / 1$ of the cephalad vertebra were tested for construct stiffness. The peak von Mises stress (MPa) at the failure point and the site of failure were measured as outcomes. A cadaveric validation study also conducted to validate the finite element model.

Results: For axial loading, the maximum stress points were at the titanium mesh cage, with maximum stress of 44 , $598 \mathrm{MPa}$, 23,505 MPa, 23,778 MPa, and 16,598 MPa, 10,172 MPa, 10,805 MPa in the 1/3, 1/2, 2/3, 3/4, 4/5, and 1/1 diameter model, respectively. For torsional load, the maximum stress point in each of the cages was identified at the rod area of the spondylectomy site, with maximum stress of $390.9 \mathrm{MPa}$ (failed at 4459 cycles), $141.35 \mathrm{MPa}$, $70.098 \mathrm{MPa}$, and $88.972 \mathrm{MPa}$, 42.249 MPa, $15.827 \mathrm{MPa}$, respectively. A cadaveric validation study results were coincided with the finite element model results.

\footnotetext{
* Correspondence: permpa@kku.ac.th

'Department of Orthopedics, Faculty of Medicine, Khon Kaen University, Khon Kaen 40002, Thailand

${ }^{2}$ Musculoskeletal Oncology Research Group, Khon Kaen University, Khon Kaen, Thailand

Full list of author information is available at the end of the article
}

C C The Author(s). 2021 Open Access This article is licensed under a Creative Commons Attribution 4.0 International License, which permits use, sharing, adaptation, distribution and reproduction in any medium or format, as long as you give appropriate credit to the original author(s) and the source, provide a link to the Creative Commons licence, and indicate if changes were made. The images or other third party material in this article are included in the article's Creative Commons licence, unless indicated otherwise in a credit line to the material. If material is not included in the article's Creative Commons licence and your intended use is not permitted by statutory regulation or exceeds the permitted use, you will need to obtain permission directly from the copyright holder. To view a copy of this licence, visit http://creativecommons.org/licenses/by/4.0/. The Creative Commons Public Domain Dedication waiver (http://creativecommons.org/publicdomain/zero/1.0/) applies to the data made available in this article, unless otherwise stated in a credit line to the data. 
(Continued from previous page)

Conclusion: The most appropriate mesh cage diameter for reconstruction is $1 / 1$ the diameter of the lower endplate of the adjacent cephalad vertebra, due to its ability to withstand both axial and torsional stress. According to the difficulty of large size cage insertion, a cage diameter of more than half of the upper endplate of the caudad vertebrae is acceptable in term of withstand stress. A cage diameter of 1/3 is unacceptable for reconstruction after total en bloc spondylectomy.

Keywords: Total en bloc spondylectomy; TES, Finite element model, Construct rigidity, Anterior Reconstruction, Titanium mesh cage diameter

\section{Introduction}

Total en bloc spondylectomy (TES) is a procedure aimed at total removal of spinal tumors [1, 2]. Successful TES results in a lower local recurrence rate and better prognosis in primary spinal tumor and secondary spinal metastasis patients [3-7]. However, achieving total resection with TES also results in structural spinal nstability, which requires circumferential reconstruction using pedicular screws and rods and anterior column reconstruction using an autologous bone graft [2, 8-10]. Even with rigid stabilization and fixation, hardware failure is a late post-operative complication in TES. Bandiera et al. reported a $7 \%$ hardware failure in TES patients and proposed that it might be due to short segment fixation and late imbalance of the spinal column. Park et al. found that $37.5 \%$ of TES patients experienced titanium rod fracture, which occurred at an average of 29.2 months and that lumbar location and history of radiation therapy were risk factors for implant failure [11].

An expandable titanium cage, titanium mesh cage, and allogenous strut bone graft are options for anterior spinal column support in reconstruction after TES [3, 7, 9, 11-13]. The study by Park et al. mentioned above also found that the mode of anterior column reconstruction was not significantly related to rod fracture [11]. Even less common, the anterior cage breakage or cage subsidence can be occurred and usually required revision surgery [14-16]. To the best of our knowledge, there is limited information available regarding the appropriate implant diameter to be used in anterior spinal column reconstruction after TES.

The objective of this study was to determine the most appropriate diameter of titanium mesh cage to be used in anterior spinal column reconstruction after singlelevel lumbar TES surgery.

\section{Methods}

A finite element model (FEM) of the lumbar spine was created using a normal CT of the lumbar spine. A Young's modulus of $17,000 \mathrm{MPa}$ and Poisson's ratio of 0.3 was applied to all vertebrae cortical bone. For cancellous bone and intervertebral disk, a Young's modulus of
$100 \mathrm{MPa}$ and 7.5 MPa and Poisson's ratio of 0.2 and 0.4 were applied in order.

The third lumbar vertebra and the adjacent intervertebral disks were removed to imitate a single level TES model. Models of six diameters of titanium mesh cage $(1 / 3,1 / 2,2 / 3,3 / 4,4 / 5$ of the diameter of the caudad vertebra), and $1 / 1$ of the diameter of the cephalad vertebra were created using a Young's modulus of 35,000 $\mathrm{MPa}$ and Poisson's ratio of 0.36 as Akamaru et al. [17]. Pedicle screws of $6 \mathrm{~mm}$ in diameter and $45 \mathrm{~mm}$ in length and a rod of $5.5 \mathrm{~mm}$ in diameter were created using the Young's modulus of $110,000 \mathrm{MPa}$ and suing the same Poisson's ratio as the same as the titanium mesh cage (Fig. 1). The screws were securely inserted into the pedicle and vertebral bodies of two spinal levels above and below on both sides and the rods were created to securely attach to all pedicle screws on both sides as a single unit. All material of each was set to be isotropic and homogenous. We decided to use the reconstruction construct of 2 levels above and below spondylectomy according to the previous literatures $[8,9,17]$.

The finite element models were created using ANSYS 14.5 (Ansys Inc., Canonsburg, Pennsylvania, USA).

We tested each model for force in both the axial and torsional load directions. The axial load was applied to each model until it reached the failure point, which was defined as the point at which the instrumentation system or spinal unit moved more than $3 \mathrm{~mm}$ in any direction. The maximum stress $(\mathrm{MPa})$ and maximum stress point were recorded. The axial load force was set at $1000 \mathrm{~N}$. Torsional stress of $5 \mathrm{~N}$-m was used to test at each model and applied until the failure point was reached. The peak von Mises stress value (MPa) of each model was recorded.

\section{Results}

The results of the compression and rotation loads in all four models are shown in Table 1.

The 1/1 diameter cage exhibited the greatest stiffness under an axial compression load of $1000 \mathrm{~N}$ until failure. The 4/5 cage diameter also performed well under axial compression load. The $1 / 3$ diameter cage was the 

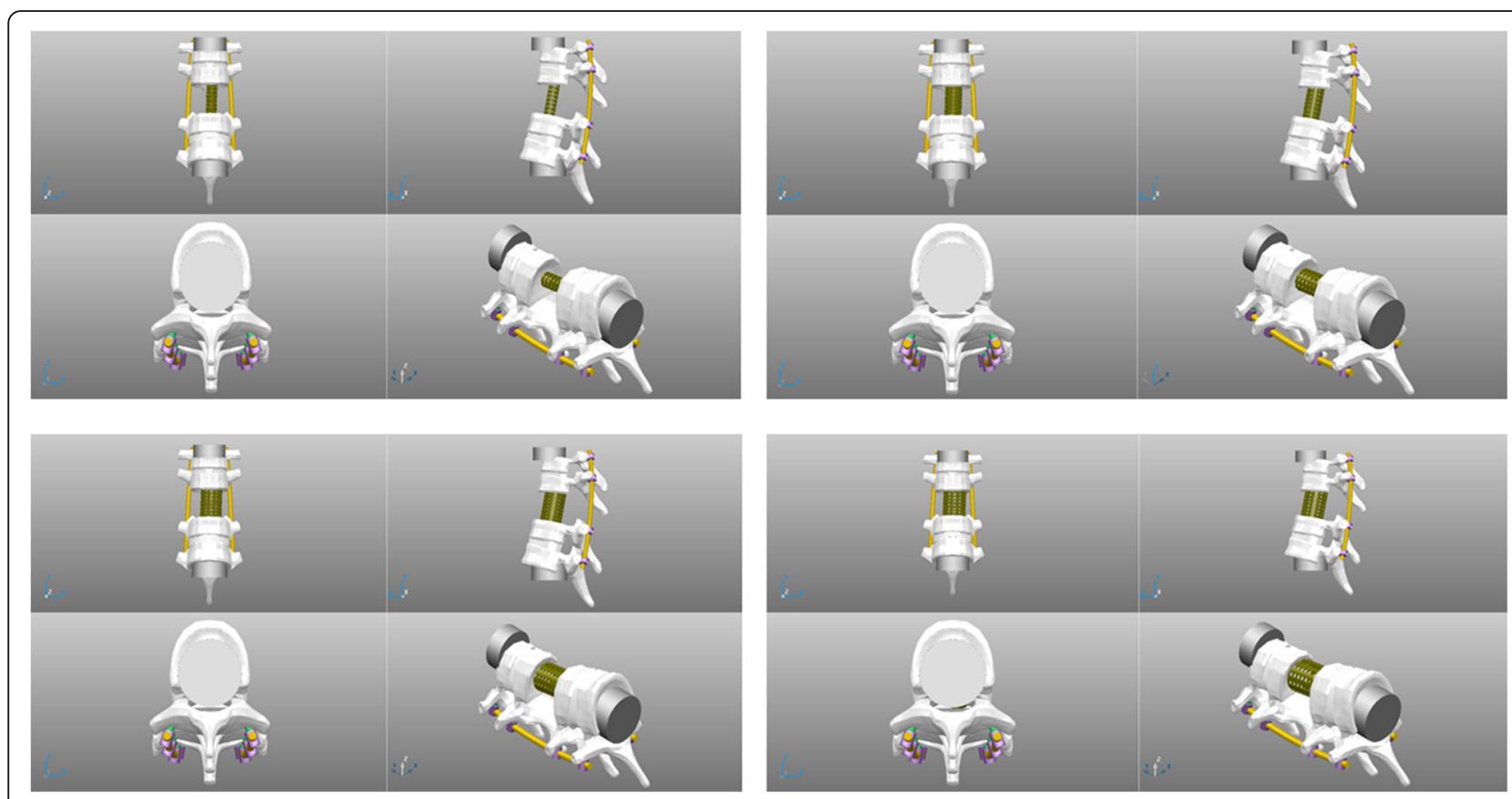

Fig. 1 The finite element of four titanium mesh cage diameter models in single third lumbar spine total en bloc spondylectomy (TES)

weakest model, and the $1 / 2$ and $2 / 3$ diameter models performed similarly.

The 1/3 diameter model failed at a von Mises stress value of 390.9 with only 4459 cycles of $5 \mathrm{~N}-\mathrm{M}$ torsional load. The $1 / 1$ diameter model exhibited the greatest stiffness under torsional load. The $2 / 3$ diameter cage exhibited greater stiffness when compare to $3 / 4$ diameter cage and the Von Mises stress value was similar to that of the $3 / 4$ diameter model.

The maximum stress load point, under axial compression load was at the upper-anterior part of the titanium mesh cage in the $1 / 3$ diameter model, lower-anterior part of the titanium mesh cage in the $1 / 2$ diameter model and $2 / 3$ diameter models, at the lower-posterior part of the titanium mesh cage in the $3 / 4$ and $4 / 5$ diameter model, and at the cephalad vertebra in $1 / 1$ model. The maximum stress point under torsional load in all models was at the rod just below the cephalad adjacent vertebra pedicle screw in all models except the $1 / 1$ model (Figs. 2, 3, and 4).

The additional cadaveric experiments using Lumbar spines (L-spine) of a human cadaver were conducted to evaluate the validity of the FEM model as well as our research results' credibility.

After removed, the first to the fifth L-spines from a fresh cadaver (a 51-year-old female, cause of death: cardiac arrest) stored at Khon Kaen University, and constructed a model simulating a case of total spondylectomy of the third L-spine. We fixed L-spines with a pedicle screw system (Suiren ${ }^{\circ}$ system by KiSCO CO., LTD., Kobe, Japan), then constructed three cylindrical spinal cages $(3 \mathrm{~cm}$ in height with three different diameters; one-third, half, and two-third of the fourth L-spine width) with photo-curing

Table 1 The peak von miles stress under the compression and torsional load to system failure

\begin{tabular}{lll}
\hline Model of titanium mesh cage & $\begin{array}{l}\text { Peak von Mises stress under compression load to } \\
\text { failure }(\mathbf{M P a})\end{array}$ & $\begin{array}{l}\text { Peak von Mises stress under torsional load to } \\
\text { failure (MPa) }\end{array}$ \\
\hline Diameter 1/3 & 44,598 & 390.9 (break at 4459 cycles) \\
Diameter 1/2 & 23,505 & 141.35 (>1 million cycle) \\
Diameter 2/3 & 23,778 & 70.098 (>1 million cycle) \\
Diameter 3/4 & 16,598 & $88.972(>1$ million cycle) \\
Diameter 4/5 & 10,172 & 42.249 (>1 million cycle) \\
Diameter 1 (same diameter as cephalad & 10,805 & 15.827 (>1 million cycle) \\
vertebra) &
\end{tabular}



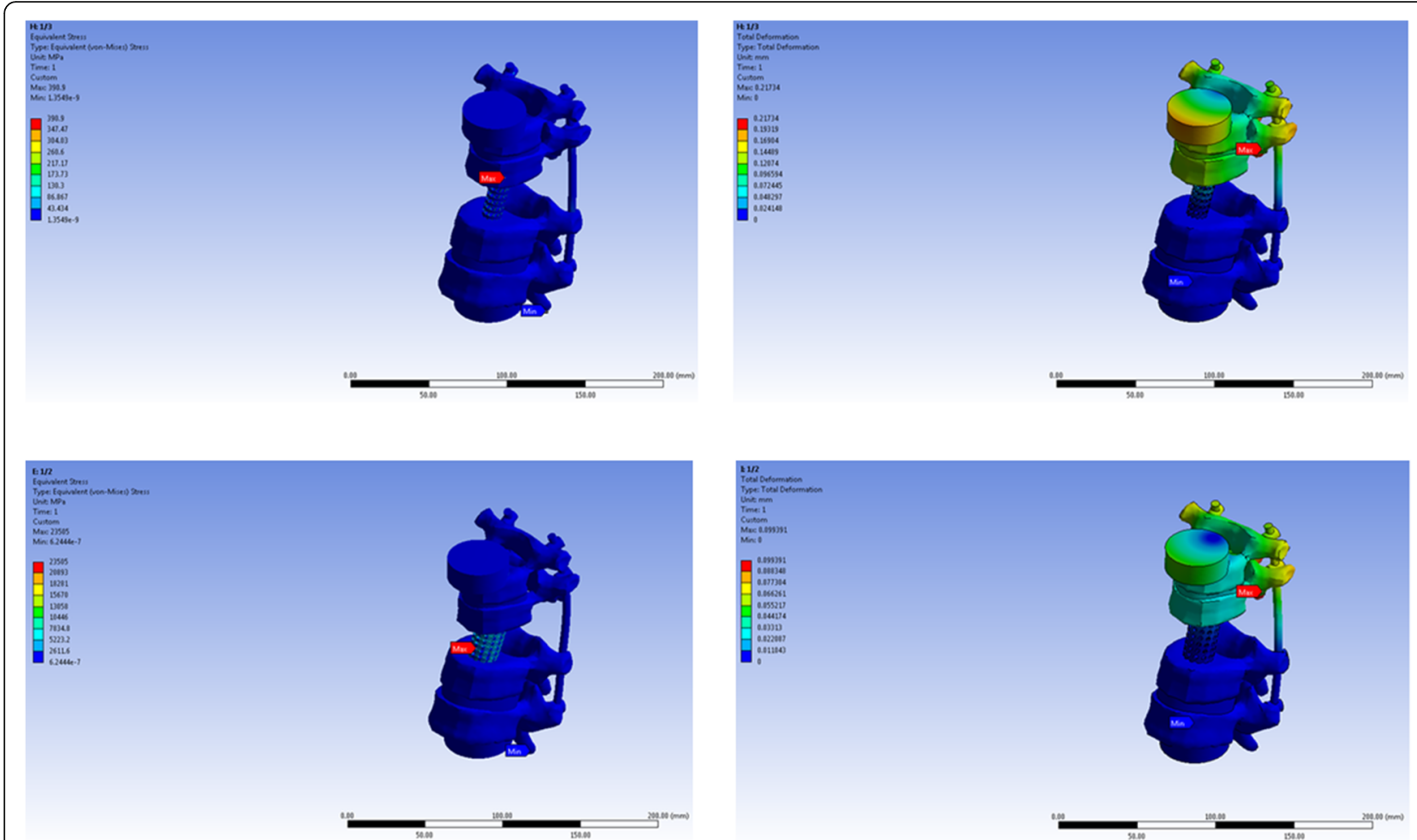

Fig. 2 The maximum stress point on finite element model of $1 / 3$ and $1 / 2$ titanium mesh cage diameter model under axial and torsional load
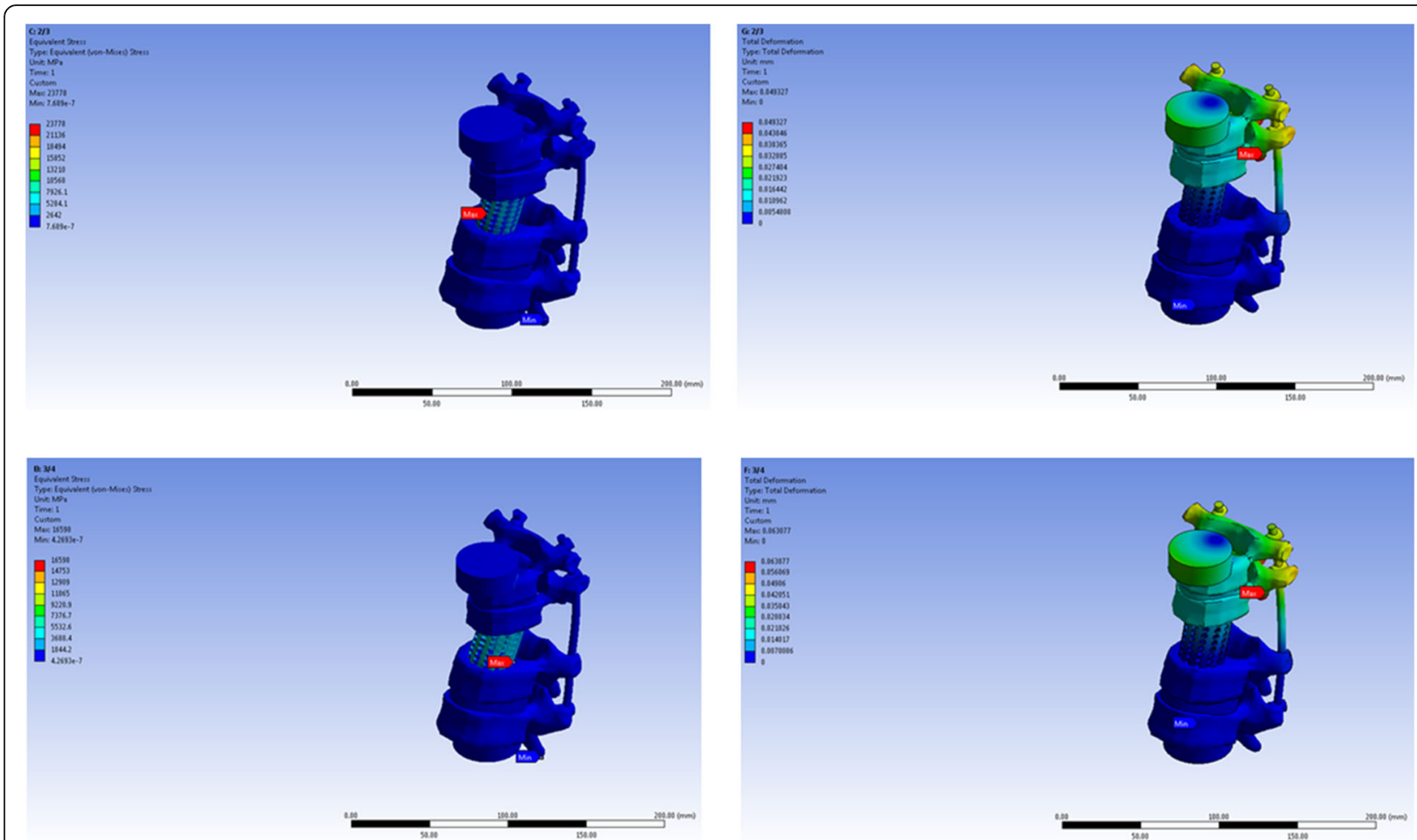

Fig. 3 The maximum stress point on finite element model of $2 / 3$ and $3 / 4$ titanium mesh cage diameter model under axial and torsional load 

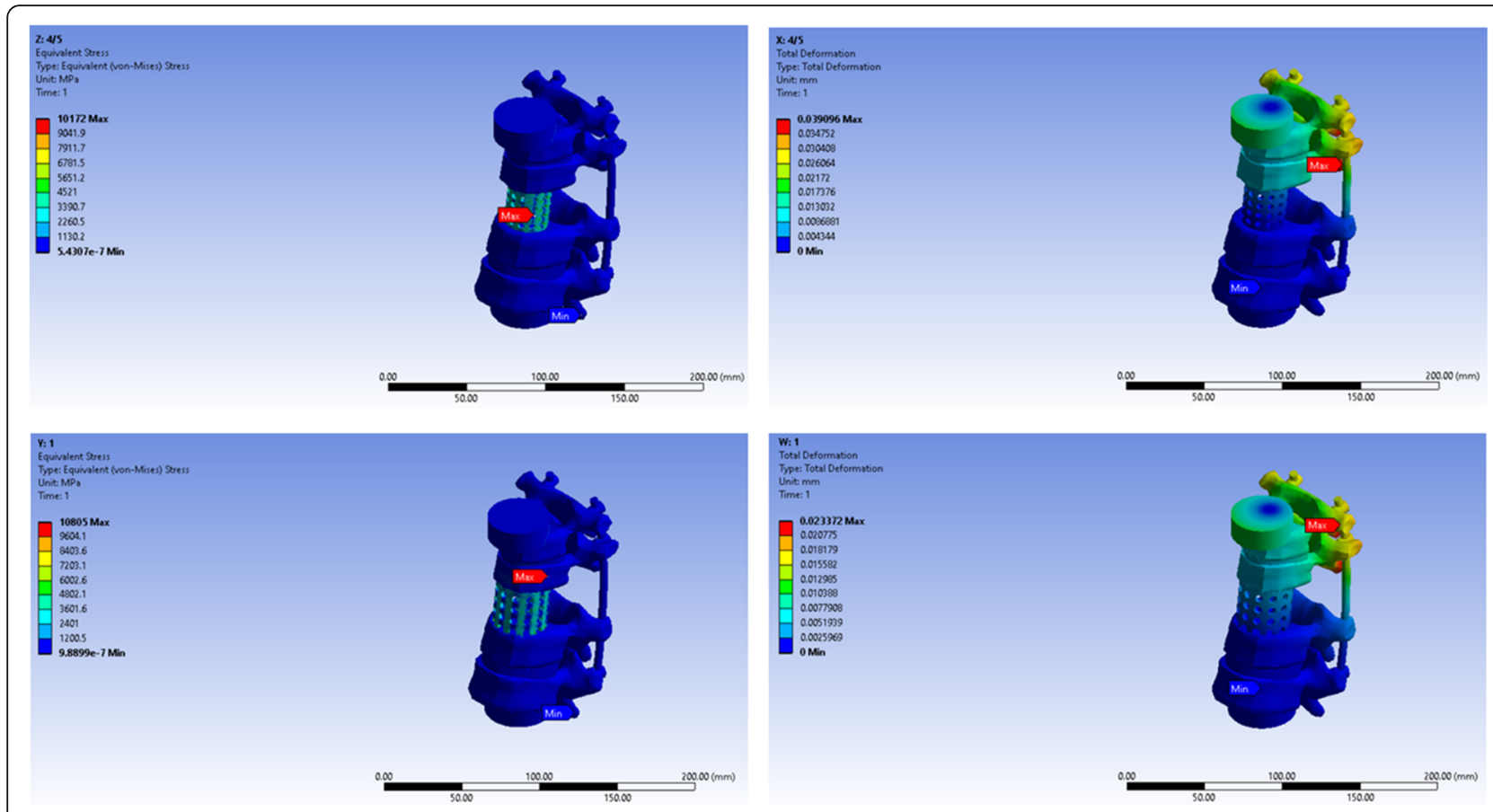

Fig. 4 The maximum stress point on finite element model of 4/5 and 1/1 titanium mesh cage diameter model under axial and torsional load

resins (SCR735), and attached strain gages in front and back at the center of right and left rods as well as in front and back at the center of each cage (Fig. 5).

As the test device, Instron's Electropuls E10000TM (Grove City, Pennsylvania, USA) was used. We then conducted compression tests under the initial compression load of $100 \mathrm{~N}$ up to $500 \mathrm{~N}$ (with the compression speed of $0.1 \mathrm{~mm} / \mathrm{s}$ ) as well as rotation tests under $5 \mathrm{Nm}$ rotation force (with the rotation speed of $0.1 \mathrm{deg} / \mathrm{s}$ ) three times to obtain the amount of change in strain on the rods of both sides and on each cage in the third tests, and compared the results with the FEM data.
As for the compression test results, the amount of change in strain on spinal cages showed $-2578 \mu \varepsilon$ at front $-1823 \mu \varepsilon$ at the back in the test using one-third width cage, $-1441 \mu \varepsilon$ at front $/-424 \mu \varepsilon$ at the back with the half-width cage, and $-851 \mu \varepsilon$ at front $/-141 \mu \varepsilon$ at the back with using the two-third width cage, respectively, indicating a decreasing tendency in strain amount according to the increase of the cage diameter.

As for the rotation test results of the amount of change in strain on rods showed $1356 \mu \varepsilon$ at front/-1250 $\mu \varepsilon$ at the back in the right side rod and $913 \mu \varepsilon$ at front/
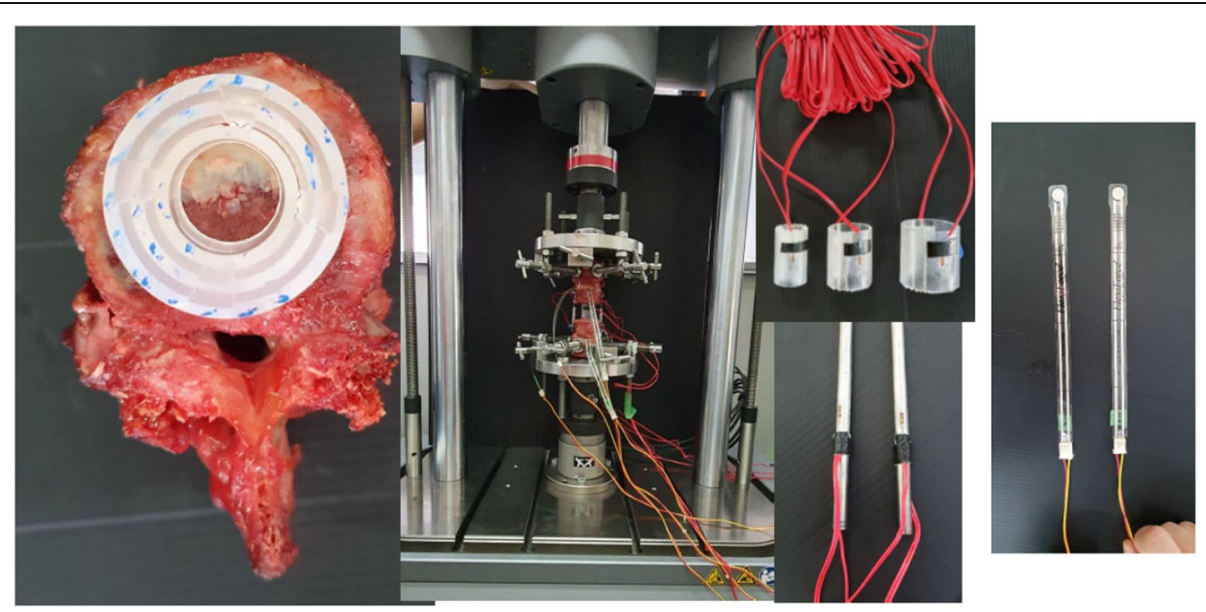

Fig. 5 Cadaveric validation test of various diameter cage diameter models using Instron's Electropuls E10000TM (Grove City, Pennsylvania, USA) machine. The stain gages were attached to the rods 
$-875 \mu \varepsilon$ at the back in the left side rod in the test using the one-third width cage, showing cage dislodgement during the loading test (Fig.6). Regarding the results of the other tests, the change amount in strain showed 373 $\varepsilon$ at front/- $472 \mu \varepsilon$ at the back in the right side rod and $187 \mu \varepsilon$ at front/ $-102 \mu \varepsilon$ at the back in the left side rod in the test using the half-width cage, $28 \mu \mu \varepsilon$ at front/ $-80 \mu \varepsilon$ at the back in the right side rod, and $160 \mu \varepsilon$ at front $/-135 \mu \varepsilon$ at the back in the left side rod with the two-third width cage, respectively. We did not confirm cage dislodgement in these tests, which also demonstrated the decreasing tendency in strain amount according to the increase of the cage diameter .

These validation tests showed a tendency coinciding with the FEM results, demonstrating the validity of the FEM model as well as the credibility of the FEM analysis in our present study.

\section{Discussion}

In order to achieve stable fixation and bone fusion, the reconstruction method of choice is two cephalad and caudad spinal levels adjacent to TES level pedicle screws

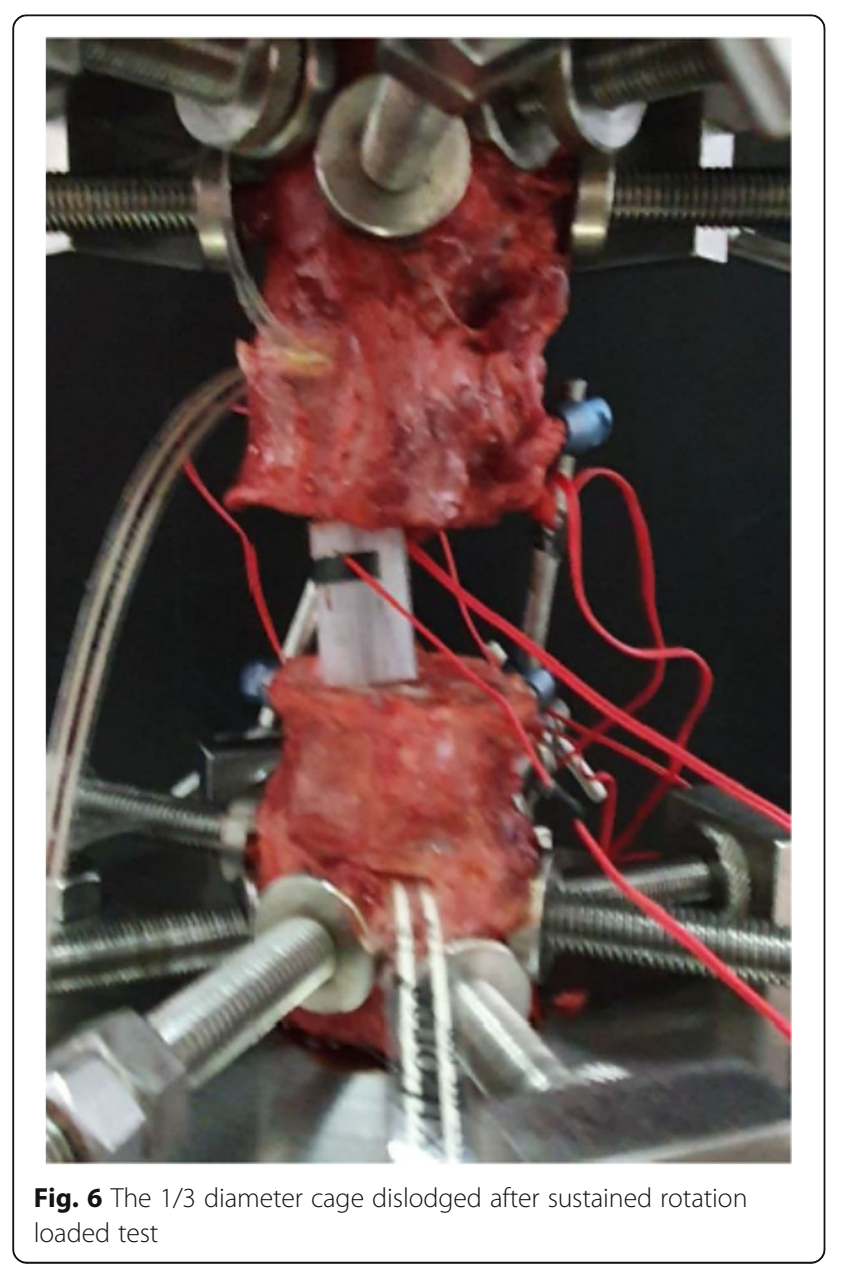

and rod fixation adjunct with anterior spinal reconstruction with cage [17].

Anterior spinal reconstruction is one of the most important steps to achieve stable fixation after TES $[9,14]$, and titanium mesh and expandable cages are commonly used implants for anterior spinal support $[2,3,7-9,12$, $18,19]$. The advantages of the titanium mesh cage are that it varies in diameter and height, allows for more space for mercerized autogenous bone graft, is resistant to subsidence, and enables stable spinal reconstruction.

The most common implant-related failure after TES is breakage of the pedicular screws and rods system $[3,10$, $11,14]$, which can come under greater stress in cases of titanium mesh cage failure. The mechanical strength of the titanium mesh cage depends on its diameter and the biomaterial. Our finite element study found that the larger diameter the stiffer resistance to load. The 1/1 and $4 / 5$ models showed the stiffest resistance to both axial compression and torsional load. The $2 / 3$ diameter cage exhibited the stiffer resistance to compression load than the $3 / 4$ and $1 / 2$ models. Against torsional load, beside $4 / 5$ and $1 / 1$ model, the $2 / 3$ diameter cage was the stiffest. Under torsional load, failure of the construct only occurred in the $1 / 3$ diameter cage. In addition, we found that the maximum stress point under compression load was the titanium mesh, suggesting that it is susceptible to breakage after axial compression stress. However, under torsional load, stress was greatest at the rod, making rod breakage the greatest concern in these cases.

Even the $1 / 1$ and $4 / 5$ models showed the best results in term of stiffness under axial compression and torsional load. The insertion of the large titanium mesh cage in between the vertebrae at the spondylectomy during operation was difficult and had the risk of impingement to the thecal sac. The smaller cage, easier for insertion, the $2 / 3$ and $3 / 4$ diameter cages exhibited the appropriate stiffness under axial and torsional load. The $1 / 2$ diameter cage was able to bear nearly the same compression load as the $2 / 3$ diameter cage but was weaker against torsional load.

Regarding cage dislodgement under torsional load, the instantaneous axis of rotation (IAR) in the spine of healthy subjects in normal conditions is usually posterior to the anulus or near the center of the anterior spinal canal $[20,21]$. When the pedicle screw system is inserted, however, the IAR would move backward, close to the middle point of the spinal rods on the left and right sides [22]. Therefore, when the distance between IAR and the spinal cage, or socalled lever arm length should be extended, relatively stronger rotational torque would be applied to cages, which should possibly lead to cage dislodgement if the cage itself is not stable enough. Thus, the cage 
diameter should be a vital factor to consider in the sense of cage stability.

Based on the above results, the $4 / 5$ and $1 / 1$ diameter cages are recommended to be used as the implant of choice to achieve rigid spinal reconstruction for both anterior and posterior approaches of TES. But very big cages cannot be used for only posterior approach of TES due to some difficulties of surgical procedures. Thus, if the larger-diameter cages are not available (which is often the case in developing countries), a $2 / 3$ and $3 / 4$ diameter titanium mesh cages are also acceptable for use as an anterior spinal column reconstruction device after TES. The $1 / 2$ diameter cage is least diameter which acceptable to use after spondylectomy.

This study was limited in that (a) it was based on a single level lumbar spine finite element model which might not account for thoracic spine and (b) that further cadaveric biomechanical study is needed.

In conclusion, a titanium mesh cage with a diameter of more than half vertebral body diameter can withstand compression-load and torsional-load stress without construction failure. Smaller cages should not be used in anterior column reconstruction after single-level TES in the lumbar spine.

\section{Abbreviations}

TES: Total en bloc spondylectomy; FEM: Finite element model

\section{Acknowledgements}

This study was granted by Faculty of Medicine, Khon Kaen University, Thailand, and supported by Research and Graduate Studies, Khon Kaen University. The authors thank the Department of Orthopedics, Faculty of Medicine, and Musculoskeletal Oncology and Spinal Disorder Research Group Khon Kaen University for support.

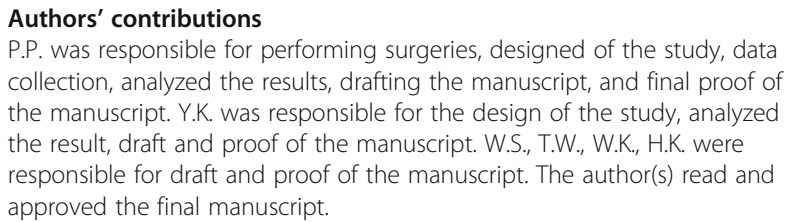
collection, analyzed the results, drafting the manuscript, and final proof of the manuscript. Y.K. was responsible for the design of the study, analyzed the result, draft and proof of the manuscript. W.S., T.W., W.K., H.K. were responsible for draft and proof of the manuscript. The author(s) read and approved the final manuscript.

\section{Funding}

This study was granted by Faculty of Medicine, Khon Kaen University, Thailand, and supported by Research and Graduate Studies, Khon Kaen University.

\section{Availability of data and materials}

Not applicable.

\section{Declaration}

\section{Ethics approval and consent to participate}

This study was approved by the institute's ethical committee (HE611293).

\section{Consent for publication}

Not applicable.

\section{Competing interests}

All authors declared no conflict of interest.

\section{Author details}

'Department of Orthopedics, Faculty of Medicine, Khon Kaen University, Khon Kaen 40002, Thailand. '2Musculoskeletal Oncology Research Group, Khon Kaen University, Khon Kaen, Thailand. ${ }^{3}$ Department of Orthopedic Surgery, Graduate School of Medical Sciences, Nagoya City University, Nagoya, Japan.

Received: 8 January 2021 Accepted: 24 February 2021

Published online: 09 March 2021

\section{References}

1. Boriani S, Gasbarrini A, Bandiera S, Ghermandi R, Lador R. Predictors for surgical complications of en bloc resections in the spine: review of 220 cases treated by the same team. Eur Spine J. 2016;25(12):3932-41. https:// doi.org/10.1007/s00586-016-4463-y.

2. Kawahara N, Tomita K, Murakami H, Demura S. Total en bloc spondylectomy for spinal tumors: surgical techniques and related basic background. Orthop Clin N Am. 2009;40(1):47. https://doi.org/10.1016/j.ocl.2008.09.004.

3. Amendola L, Cappuccio M, De lure F, Bandiera S, Gasbarrini A, Boriani S. En bloc resections for primary spinal tumors in 20 years of experience: effectiveness and safety. Spine J. 2014;14(11):2608-17. https://doi.org/10.101 6/j.spinee.2014.02.030.

4. Kato S, Murakami H, Demura S, et al. More than 10-year follow-up after total en bloc spondylectomy for spinal tumors. Ann Surg Oncol. 2014;21(4):13306. https://doi.org/10.1245/s10434-013-3333-7.

5. Matsumoto M, Tsuji T, Iwanami A, et al. Total en bloc spondylectomy for spinal metastasis of differentiated thyroid cancers a long-term follow-up. J Spinal Disord Tech. 2013;26(4):E137-42. https://doi.org/10.1097/BSD.0b013 e318278c8e4.

6. Stener B. Complete removal of vertebrae for extirpation of tumors. A 20year experience. Clin Orthop Relat Res. 1989;245:72-82.

7. Kawahara N, Tomita K, Matsumoto T, Fujita T. Total en bloc spondylectomy for primary malignant vertebral tumors. Chir Organi Mov. 1998:83(1-2):73-86.

8. Tomita K, Kawahara N, Baba H, Tsuchiya H, Fujita T, Toribatake Y. Total en bloc spondylectomy. A new surgical technique for primary malignant vertebral tumors. Spine (Phila Pa 1976). 1997;22(3):324-33. https://doi.org/1 0.1097/00007632-199702010-00018

9. Tomita K, Kawahara N, Murakami H, Demura S. Total en bloc spondylectomy for spinal tumors: improvement of the technique and its associated basic background. J Orthop Sci. 2006;11(1):3-12. https://doi.org/10.1007/s00776005-0964-y.

10. Bandiera S, Boriani S, Donthineni R, Amendola L, Cappuccio M, Gasbarrini A. Complications of en bloc resections in the spine. Orthop Clin North Am. 2009;40(1):125-31, vii. https://doi.org/10.1016/j.ocl.2008.10.002.

11. Park SJ, Lee CS, Chang BS, et al. Rod fracture and related factors after total en bloc spondylectomy. Spine J. 2019;19(10):1613-9. https://doi.org/10.101 6/j.spinee.2019.04.018.

12. Shimizu T, Murakami H, Demura S, et al. Total en bloc spondylectomy for primary tumors of the lumbar spine. Medicine (Baltimore). 2018:97(37): e12366. https://doi.org/10.1097/MD.0000000000012366.

13. Yokogawa N, Murakami H, Demura S, et al. Perioperative complications of total en bloc spondylectomy: adverse effects of preoperative irradiation. Plos One. 2014;9(6):e98797. https://doi.org/10.1371/journal.pone.0098797.

14. Matsumoto $M$, Watanabe $K_{\text {, Tsuji }}$, et al. Late instrumentation failure after total en bloc spondylectomy. J Neurosurg Spine. 2011;15(3):320-7. https:// doi.org/10.3171/2011.5.SPINE10813.

15. Yoshioka K, Murakami H, Demura S, et al. Clinical outcome of spinal reconstruction after total en bloc spondylectomy at 3 or more levels. Spine (Phila Pa 1976). 2013;38(24):E1511-6. https://doi.org/10.1097/BRS.0b013e3182a6427a.

16. Yoshioka K, Murakami H, Demura S, et al. Risk factors of instrumentation failure after multilevel total en bloc spondylectomy. Spine Surg Relat Res. 2017;1(1):31-9. https://doi.org/10.22603/ssrr.1.2016-0005.

17. Akamaru T, Kawahara N, Sakamoto J, et al. The transmission of stress to grafted bone inside a titanium mesh cage used in anterior column reconstruction after total spondylectomy: a finite-element analysis. Spine (Phila Pa 1976). 2005;30(24):2783-7. https://doi.org/10.1097/01.brs.00001922 81.53603.3f.

18. Ishii T, Murakami H, Demura S, et al. Invasiveness reduction of recent total en bloc spondylectomy: assessment of the learning curve. Asian Spine J. 2016;10(3):522-7. https://doi.org/10.4184/asj.2016.10.3.522. 
19. Yonezawa N, Murakami H, Kato S, Takeuchi A, Tsuchiya H. Giant cell tumor of the thoracic spine completely removed by total spondylectomy after neoadjuvant denosumab therapy. Eur Spine J. 2017;26(Suppl 1):236-42. https://doi.org/10.1007/s00586-017-5086-7.

20. Haher TR, O'Brien M, Felmly WT, et al. Instantaneous axis of rotation as a function of the three columns of the spine. Spine (Phila Pa 1976). 1992;17(6 Suppl):S149-54. https://doi.org/10.1097/00007632-199206001-00015.

21. Wachowski MM, Mansour M, Lee $C$, et al. How do spinal segments move? J Biomech. 2009;42(14):2286-93. https://doi.org/10.1016/j. jbiomech.2009.06.055.

22. Inoue M, Mizuno T, Sakakibara T, et al. Trajectory of instantaneous axis of rotation in fixed lumbar spine with instrumentation. J Orthop Surg Res. 2017;12(1):177. https://doi.org/10.1186/s13018-017-0677-x.

\section{Publisher's Note}

Springer Nature remains neutral with regard to jurisdictional claims in published maps and institutional affiliations.

Ready to submit your research? Choose BMC and benefit from:

- fast, convenient online submission

- thorough peer review by experienced researchers in your field

- rapid publication on acceptance

- support for research data, including large and complex data types

- gold Open Access which fosters wider collaboration and increased citations

- maximum visibility for your research: over $100 \mathrm{M}$ website views per year

At BMC, research is always in progress.

Learn more biomedcentral.com/submissions 